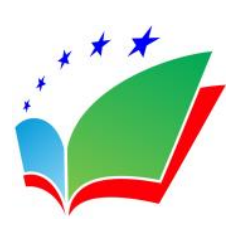

European Journal of Fitness, Nutrition and Sport Medicine Studies

ISSN: 2668 - 9758

ISSN-L: 2668 - 9758

Available on-line at: $\underline{\text { www.oapub.org/hlt }}$

\title{
HOW DOES PARTICIPATION IN PHYSICAL ACTIVITY AFFECT PHYSICAL FITNESS ELEMENTS IN CHILDREN AGED 5-9?
}

\author{
Aslihan Buksur ${ }^{1}$, \\ Umut Canli ${ }^{2 i}$, \\ Cüneyt Taskin ${ }^{3}$ \\ 1,2School of Physical Education and Sports, \\ Tekirdag Namik Kemal University, \\ Turkey \\ ${ }^{3}$ Kirkpinar Sport Faculty, \\ Trakya University, \\ Turkey
}

\begin{abstract}
:
This study was conducted to examine the effect of participation in physical activity on physical fitness parameters in children aged 5-9 years. A total of 83 children, 44 girls, and 39 boys, studying in a private primary school participated in the study voluntarily. The Eurofit Test Battery was used to evaluate the physical fitness levels of children. Within the scope of the Eurofit test battery; the body weight and height values of the children were measured. In the determination of motoric performances, flamingo balance, disc touch, sit-reach, standing long jump, sit-up, bent-arm hanging, and 5x10 meter sit-up tests were used. A personal information form prepared by the researchers was used to determine demographic characteristics. Whether the data is normally distributed or not was checked with kurtosis and skewness values. In the statistical analysis dimension; descriptive analysis (mean, standard deviation, median, min-max value, ratio, frequency), independent samples $t$ test (Independent Samples $t$ test) were used. In terms of children having an athlete license, a significant difference was found in their height, standing long jump test, sit-up test, bent-arm hanging test, 5x10 meter sit-up run test scores ( $>0.05)$. A significant difference was found in the findings of height, body weight, standing long jump test, sit-up test, bent arm hanging test, 5x10 meter sit-up run test in terms of children's participation in traditional children's games $(p>0.05)$. As a result, it has been determined that children's having an athlete's license increases their height, explosive strength, core strength endurance, upper extremity strength endurance, agility, and again, the students' participation in traditional children's games has positive effect on height, body weight, explosive strength, core strength endurance, upper extremity strength endurance and agility.
\end{abstract}

i Correspondence: email ucanli@nku.edu.tr 
Keywords: physical fitness, primary school students, physical activity

\section{Introduction}

While physical activity is accepted as one of the main determinants of physical fitness, physical fitness is also considered as one of the most important indicators of health (Ortega, Ruiz, Castillo and Sjostrom, 2008). Although physical activity level is a determinant of cardiovascular risks in children, it has been reported that it is positively associated with the development of aerobic capacity (Lopes, Rodrigues, Maia and Malina, 2011) and low muscle strength and low cardiopulmonary fitness are associated with low bone density, metabolic risk factors, and cardiovascular diseases (Smith et al., 2014). It is reported that regular physical activity in children increases cardiovascular system endurance and muscular fitness, improves bone health, cardiovascular fitness, and body composition. From this, it has been proven that children who participate in physical activity regularly are more likely to be healthier in adulthood (Health and Services, 2008). However, as a result of the research; it has been determined that the physical activity levels of school-age children have decreased significantly in the last twenty years (Janssen, Katzmarzyk, Boyce, King and Pickett, 2004). At the same time, it has been observed that the physical fitness levels of children have deteriorated in recent years (Aydemir and Bayansalduz, 2019).

It is known that there are many factors that affect the physical fitness level of children. One of these factors is the rapid developments in today's technology. With the increasing technology addiction in children, they live a static and stable life. (Kandir and Tumer, 2013). In this process, it was determined that the number of children playing in the streets and playgrounds decreased, and children spent less time in free areas and site gardens. Therefore, it is thought that this situation affects children's movement development negatively (Taskin and Ozdemir, 2018).

The primary school period in children is considered the most important period in terms of motor development. It has been determined that there are studies examining the environmental factors affecting the physical fitness elements of children in this period and the level of their impact, but this number is insufficient. In addition, no research has been found that correlates children's physical fitness with parameters such as children's participation in traditional children's games and children's athlete licenses. Therefore, considering that the findings to be obtained here will contribute to the literature, the importance of the research increases. At the stage of interpretation of research results; it is thought that the determination of the factors affecting the physical fitness level of children can contribute to the development of processes such as suggestion and guidance. In addition, the fact that suggestions and opinions about the incentives for participation in physical activity, physical fitness, and measures for motor development processes can be put forward increases the importance of the research. In this direction, the purpose of the research is to reveal how children aged 5-9 who are studying in primary school have 
an athlete license and participate in traditional children's games, to what extent they affect the physical fitness factors of children.

\section{Method}

\subsection{Model of the Research}

The research was designed according to the descriptive survey model, which is one of the general survey designs. When we examine the general features of the scanning model; it is seen that there are models that aim to collect data to determine certain characteristics of a group, or that the views of the participants about a subject or event or their characteristics such as interests, skills, abilities and attitudes are determined (Buyukozturk et al., 2016).

\subsection{Research Group}

The research group consists of girls and boys who study in grades 1,2,3 and 4 in a private school. As the research group, it was aimed to reach all children who study in primary school. An informed volunteer and parent consent form containing the detailed research scope was sent to the parents. Children of parents who signed the form and agreed to participate in the research were included in the study. Accordingly, a total of 83 children, 44 girls and 39 boys, participated in the study voluntarily. Information on the age, gender and grade levels of the children is detailed in Table 1.

Table 1: Frequency and percentage distributions of children according to age, gender, and grade levels

\begin{tabular}{|l|c|c|}
\hline Variables & Frequency & Percentage Distribution (\%) \\
\hline Age (year) & 3 & 3.6 \\
\hline 5 years old & 20 & 24.1 \\
\hline 6 years old & 23 & 27.7 \\
\hline 7 years old & 27 & 32.5 \\
\hline 8 years old & 10 & 12.0 \\
\hline 9 years old & 44 & 53.0 \\
\hline Gender & 39 & 47.0 \\
\hline Girl & \multicolumn{2}{|}{} \\
\hline Boy & 20 & 24.1 \\
\hline Grade level & 20 & 24.1 \\
\hline Grade 1 & 21 & 25.3 \\
\hline Grade 2 & 22 & 26.5 \\
\hline Grade 3 &
\end{tabular}

\subsection{Data Collection Tools}

In the study, the personal information form containing demographic information, Eurofit Test Battery was applied to the students. Information about the measuring battery in this research is explained below. 


\subsection{Eurofit Test Battery}

\subsubsection{Height Measurement}

Height measurements of the participants were made while their feet were bare. During the measurements, attention was paid that the heads of the participants were upright, the soles of the feet were flat on the ground, the knees were tense, the heels were together, and their bodies were in an upright position. (Karakoc, 2009). Mesilife 13539 brand stadiometer with a portable, degree of accuracy of $0.1 \mathrm{~cm}$ was used to measure height. The obtained values are placed as centimetre in the information formula.

\subsubsection{Weight Measurement}

The body weights of the participants were measured with a Tanita BC 545N Bioelectrical Impedance Analyzer with a sensitivity of $0.01 \mathrm{~kg}$. The measurements of the participants were measured with bare feet and only shorts and t-shirts. Values were recorded on the measurement form in $\mathrm{kg}$ (Karakoc, 2009).

\subsubsection{Flamingo Balance Test}

It is a test used to determine the static balance property. Children try to maintain their position by using their dominant feet on the balance beam. In order to start the test process, the participants were asked to bend their non-dominant foot towards the hip and hold it with the hand on the same side. Participants were allowed to receive support from the researchers so that they could fully balance on the balance beam. The test starts when it is felt that the balance is achieved, and the aid phase is over. The aim of the participant is to maintain his balance within the framework of the rules set on the balance beam for one minute. If the participant releases his foot or touches the ground, the second is stopped. After the participant's balance is restored, the time continues. This process continues until it takes one minute. The participant's attempt to balance within one minute is recorded as the participant's score (Hazar and Tasmektepligil, 2008).

\subsubsection{Disc Touch Test}

The test equipment, which was prepared in accordance with the test protocol, was designed by the researchers on a cardboard floor with two discs in the right and left sections and a square section in the middle of the discs. The non-dominant hand of the participant is on the square. With his dominant hand, he was asked to touch the discs in the right and left sections twenty-five times. Disc touch test was made twice. The lowest time determined as a result of twenty-five touches was recorded in seconds as the participant's score (Opstoel et al., 2015).

\subsubsection{Sit-Reach Test}

It was used to determine the flexibility levels of children. In order to carry out the test, the athletes were asked to be ready either naked or wearing socks. Children sat in a long sitting position in front of the sitting bench, with the soles of their feet in contact with the flexibility bench. The children were asked not to bend their knees and to reach forward 
from their bodies, to drag the movable apparatus on the coffee table forward with their fingertips and to wait for 1-2 seconds at the last level they could reach. The measurer stood next to the athletes and prevented their knees from bending. The last position of the apparatus was recorded in centimeters. The measurement was applied twice. The highest value was evaluated as the flexibility score (Hazar and Tasmektepligil, 2008).

\subsubsection{Standing Long Jump Test}

The participant took his position behind the line determined for the application of the test. The participant was asked to take the test when he felt ready, without any commands. The distance from the starting point of the participant to the contact of the heels of the feet was measured. The standing long jump was performed twice. The longest distance from the two tests was recorded as the participant's score (Altinkok, 2006).

\subsubsection{Sit-Up Test}

It is a test to determine the core area endurance of the participants. The participants took their position lying on the floor with their knees at ninety degrees. Necessary precautions were taken by the researchers to prevent the participants' feet from losing contact with the ground during the sit-ups. The participants were asked to keep their hands on the back of the neck and the shoulders to touch the ground during the landing phase of the sit-up phase and the elbows to touch the knees during the take-off phase. The number of appropriate sit-ups for thirty seconds was recorded as the participant's score (Pekel, 2007).

\subsubsection{Bent-Arm Hanging Test}

On the platform prepared according to the height of the participants, the researchers showed the appropriate bar holding style and helped the participant until his chin was below the bar level. Students were asked to maintain their existing positions and the application was finished when their eyes fell below the bar. The time until now was recorded as the participant's score (Zahner et al., 2006).

\subsubsection{0x5 Meter Running Test}

An application area was created with a distance of five meters between two cones. One round trip of the participant between the two funnels is determined as one round trip. The participant was asked to do five laps in this way. After five laps, the running time was recorded and the test was terminated (Opstoel et al., 2015).

\subsubsection{Data Collection}

An application was made to Tekirdag Namik Kemal University Scientific Research and Publication Ethics Committee for ethics committee approval and the necessary ethics committee approval was obtained for the research (Protocol No: 2020.209.08.18). Test procedures were explained in detail to both students and parents by the researcher, both theoretically and practically. Personal information form was sent to parents. First of all, the height and body weight measurements of the students were made. Then, flamingo 
balance test, sit-reach flexibility test, disc touch test, standing long jump test, bent-arm hanging test, sit-up test and 10x5 meter sit-up run were applied respectively. Measurements and tests were applied to the participants in the same order by the same researchers. A standard warm-up of 5 minutes of jogging followed by 5 minutes of dynamic stretching was performed before all test sessions. All tests were performed at the same time of day (17:30-19:30) to avoid the influence of circadian rhythms on study results.

\subsection{Analysis of Data}

The data obtained in the research were transferred to the SPSS 18.0 program and the analyzes were made using this statistical program. In the analysis of the data, descriptive statistics (mean, standard deviation, median, min-max value, ratio, frequency, etc.) were used to define the characteristics of the research group and were expressed with the help of tables. Before the comparison of the variables, it was examined whether the assumptions of normality and homogeneity were met (Tabachnick and Fidell, 2013). As a result of this evaluation, it was determined that the variables showed normal distribution. Then, independent samples $t$ test (Independent Samples $t$ test) was used in comparison of two independent groups. Cohen's d statistics were used to calculate the strength of the relationship between the variables in the t-test analysis (Buyukozturk et al., 2016). p<0.05 was considered statistically significant.

\section{Results}

Table 2: Descriptive statistics for age, body height, and body weight of children

\begin{tabular}{|l|c|c|c|c|}
\hline Variables & Minimum & Maximum & Mean & Sd \\
\hline Age (year) & 5.0 & 9.0 & 7.25 & 1.06 \\
\hline Body height $(\mathrm{cm})$ & 115.0 & 150.0 & 131.10 & 7.93 \\
\hline Body weight $(\mathrm{kg})$ & 17.0 & 50.0 & 28.30 & 6.77 \\
\hline
\end{tabular}

The minimum age of the children participating in the study was 5 years, the maximum age was 9 years, and their average age was $7.25 \pm 1.06$ years. The minimum height of the children was $115.0 \mathrm{~cm}$, the maximum height was $150.0 \mathrm{~cm}$, and the average height was $131.10 \pm 7.93 \mathrm{~cm}$. The minimum body weight of the children was $17 \mathrm{~kg}$, the maximum body

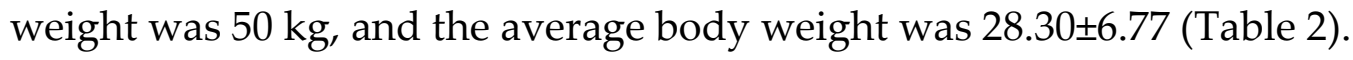

When the flamingo balance test values of the children participating in the study were examined, it was determined that a minimum of $2.0 \mathrm{n}$, a maximum of $28.0 \mathrm{n}$, and the average of the flamingo balance test were $13.22 \pm 6.85$ points. When the disc touch test values of the children were examined, it was determined that the minimum 13.7 seconds, the maximum 36.7 seconds, the disc touch test averages were $25.14 \pm 5.29$ seconds. When the sit-reach test values of the children were examined, it was determined that the minimum $16.0 \mathrm{~cm}$, the maximum $43.0 \mathrm{~cm}$, and the average of the sit-reach test were $29.14 \pm 4.70 \mathrm{~cm}$. Considering the standing long jump test values of the children, it was determined that the minimum $40.0 \mathrm{~cm}$, the maximum $165.0 \mathrm{~cm}$, and the standing long 
jump test averages were $104.84 \pm 23.89 \mathrm{~cm}$. The children's sit-up test values were determined as minimum $5.0 \mathrm{n}$, maximum $27.0 \mathrm{n}$, and the sit-up test averages were determined as $14.48 \pm 5.00$ points. The children's bent-arm hanging test values were determined as minimum $1.0 \mathrm{sec}$, maximum $15.6 \mathrm{sec}$., and the bent-arm hanging test averages were $4.76 \pm 3.52 \mathrm{sec}$. It was determined that the $5 \times 10$ meter sit-up run test values of the children were determined as minimum 30.5 seconds, maximum 57.2 seconds, and $5 \times 10$ meter sit-up run test averages as $42.15 \pm 6.95$ seconds (Table 3 ).

Table 3: Descriptive statistics for children's physical fitness parameters

\begin{tabular}{|l|c|c|c|c|}
\hline Variables & Minimum & Maximum & Mean & Sd \\
\hline Flamingo balance test $(\mathrm{n})$ & 2.0 & 28.0 & 13.22 & 6.85 \\
\hline Disc touch test $(\mathrm{sec})$ & 13.7 & 36.7 & 25.14 & 5.29 \\
\hline Sit-reach test $(\mathrm{cm})$ & 16.0 & 43.0 & 29.14 & 4.70 \\
\hline Standing long jump test $(\mathrm{cm})$ & 40.0 & 165.0 & 104.78 & 23.89 \\
\hline Sit-up test (n) & 5.0 & 27.0 & 14.48 & 5.00 \\
\hline Bent-arm hanging test (sec) & 1.0 & 15.6 & 4.76 & 3.52 \\
\hline 5x10 meter sit-up running test (sec) & 30.5 & 57.2 & 42.15 & 6.95 \\
\hline
\end{tabular}

Note: $\mathrm{cm}=$ centimeter; $\mathrm{kg}=$ kilogram; $\mathrm{n}=$ number $($ piece); $\mathrm{sec}=$ second

Table 4: Comparison of children's physical fitness parameters in terms of having an athlete license

\begin{tabular}{|c|c|c|c|c|c|c|c|c|}
\hline \multirow[t]{3}{*}{ Variables } & \multirow{2}{*}{\multicolumn{2}{|c|}{$\begin{array}{c}\begin{array}{c}\text { Having an } \\
\text { athlete license } \\
\text { (yes) }\end{array} \\
\mathrm{n}=36 \\
\end{array}$}} & \multirow{2}{*}{\multicolumn{2}{|c|}{$\begin{array}{c}\begin{array}{c}\text { Having an } \\
\text { athlete license } \\
\text { (no) }\end{array} \\
\mathrm{n}=47 \\
\end{array}$}} & \multirow[t]{3}{*}{ sd } & \multirow[t]{3}{*}{$\mathbf{t}$} & \multirow[t]{3}{*}{$\mathbf{p}$} & \multirow[t]{3}{*}{ d } \\
\hline & & & & & & & & \\
\hline & Mean & Sd & Mean & Sd & & & & \\
\hline Body height $(\mathrm{cm})$ & 133.63 & 7.48 & 129.17 & 7.79 & 81 & 2.63 & $0.01^{*}$ & 0.58 \\
\hline Body weight $(\mathrm{kg})$ & 29.16 & 5.62 & 27.63 & 7.52 & 81 & 1.01 & 0.31 & - \\
\hline Flamingo balance test (n) & 12.33 & 6.71 & 13.91 & 6.95 & 81 & -1.04 & 0.30 & - \\
\hline Disc touch test (sec) & 24.76 & 5.80 & 25.44 & 4.91 & 81 & 0.33 & 0.56 & - \\
\hline Sit-reach test $(\mathrm{cm})$ & 29.38 & 4.24 & 28.95 & 5.06 & 81 & 0.17 & 0.68 & - \\
\hline $\begin{array}{l}\text { Standing long jump test } \\
(\mathrm{cm})\end{array}$ & 111.86 & 24.69 & 99.36 & 22.01 & 81 & 2.43 & $0.01^{*}$ & 0.53 \\
\hline Sit-Up test $(n)$ & 16.25 & 4.64 & 13.12 & 4.88 & 81 & 2.94 & $0.00^{*}$ & 0.65 \\
\hline $\begin{array}{l}\text { Bent-arm hanging test } \\
\text { (sec) }\end{array}$ & 5.92 & 3.68 & 3.88 & 3.15 & 81 & 2.71 & $0.00^{*}$ & 0.85 \\
\hline $\begin{array}{l}5 \times 10 \text { meter sit-up } \\
\text { running test }(\mathrm{sec})\end{array}$ & 39.13 & 5.46 & 44.45 & 7.13 & 81,00 & -3.84 & $0.00^{*}$ & 0.79 \\
\hline
\end{tabular}

Note: $\mathrm{p}<0,05^{*} \mathrm{~d}=$ Cohen's d effect size

When the comparison of the physical fitness parameters of the children in terms of being licensed athletes is examined; there was no significant difference in body weight, flamingo balance test, disc touch test, sit-reach test values. ( $p>0.05)$. A significant difference was determined in height, standing long jump test, sit-up test, bent-arm hanging test, 5x10 meter sit-up run test $(\mathrm{p}<0.05)$. The effect sizes of the differences between the groups in the height, standing long jump and sit-up test values were determined as medium level 
(respectively; $\mathrm{d}=0.58 ; 0.53 ; 0.65)$. The effect levels of the differences between the bent-arm hanging and $5 \times 10$ meter sit-up tests values between the groups were determined to be strong. (respectively; $\mathrm{d}=0.85 ; 0.79$ ) (Table 4).

Table 5: Comparison of children's physical fitness parameters in terms of participation in traditional children's games

\begin{tabular}{|c|c|c|c|c|c|c|c|c|}
\hline \multirow[t]{3}{*}{ Variables } & \multirow{2}{*}{\multicolumn{2}{|c|}{$\begin{array}{c}\begin{array}{c}\text { Participation in } \\
\text { traditional }\end{array} \\
\text { children's games } \\
\text { (yes) }\end{array}$}} & \multirow{2}{*}{\multicolumn{2}{|c|}{$\begin{array}{c}\text { Participation in } \\
\text { traditional } \\
\text { children's games } \\
\text { (no) }\end{array}$}} & \multirow[t]{3}{*}{ sd } & \multirow[t]{3}{*}{$\mathbf{t}$} & \multirow[t]{3}{*}{$\mathbf{p}$} & \multirow[t]{3}{*}{ d } \\
\hline & & & & & & & & \\
\hline & Mean & Sd & Mean & Sd & & & & \\
\hline Body height $(\mathrm{cm})$ & 133.55 & 6.61 & 129.23 & 8.40 & 81 & 2.53 & $0.01 *$ & 0.57 \\
\hline Body weight (kg) & 30.05 & 5.67 & 26.95 & 7.27 & 81 & 2.10 & $0.03 *$ & 0.47 \\
\hline $\begin{array}{l}\text { Flamingo balance } \\
\text { test }(\mathrm{n})\end{array}$ & 12.44 & 7.24 & 13.82 & 6.55 & 81 & -0.91 & 0.36 & - \\
\hline $\begin{array}{l}\text { Disc touch test } \\
\text { (sec) }\end{array}$ & 24.00 & 5.64 & 26.02 & 4.88 & 81 & 3.04 & 0.08 & - \\
\hline $\begin{array}{l}\text { Sit-reach test } \\
(\mathrm{cm})\end{array}$ & 28.91 & 4.66 & 29.31 & 4.77 & 81 & 0.14 & 0.70 & - \\
\hline $\begin{array}{l}\text { Standing long } \\
\text { jump test }(\mathrm{cm})\end{array}$ & 113.91 & 23.72 & 97.78 & 21.78 & 81 & 3.21 & $0.00 *$ & 0.70 \\
\hline Sit-up test (n) & 16.44 & 4.34 & 12.97 & 4.99 & 81 & 3.31 & $0.00 *$ & 0.74 \\
\hline $\begin{array}{l}\text { Bent-arm } \\
\text { hanging test (sec) }\end{array}$ & 6.30 & 4.14 & 3.59 & 2.42 & 52.94 & 3.49 & $0.00 *$ & 0.79 \\
\hline $\begin{array}{l}5 \times 10 \text { meter sit-up } \\
\text { running test (sec) }\end{array}$ & 38.66 & 5.22 & 44.82 & 6.97 & 80.96 & $-4,59$ & $0.00^{*}$ & 1.00 \\
\hline
\end{tabular}

Note: $p<0,05^{*} d=$ Cohen's d effect size

When the physical fitness parameters of children are compared in terms of participation in traditional children's games; no significant difference was detected in flamingo balance test, disc touch test, sit-reach test $(\mathrm{p}>0.05)$. There was a significant difference in height, body weight, standing long jump test, sit-up test, bent arm hanging test, 5x10 meter situp run test $(p<0.05)$. The effect sizes of the differences between the groups in the values of height, body weight, standing long jump and sit-up tests were determined as medium level (respectively; $d=0.57 ; 0.47 ; 0.70 ; 0.74$ ). The effect levels of the differences between the bent arm hanging and 5x10 meter sit-up tests values between the groups were determined to be strong (respectively; $d=0.79 ; 1.00$ ) (Table 5).

\section{Discussion}

In the study, it was aimed to determine the extent to which physical activity characteristics such as 5-9-year-old children doing sports licensed in any sports branch and participating in traditional children's games affect physical fitness factors.

In the study, in the comparison of children's physical fitness elements in terms of having or not having an athlete license; a significant difference was found in favour of 
students who have an athlete license in the values of height, standing long jump test, situp test, bent-arm hanging test, 5x10 meters sit-up run test. No significant difference was found in the comparison of other physical fitness parameters between groups. In the comparison of motoric field tests measurements made by Simsek (2018) to student groups participating and not participating in school sports; it was reported that there was a significant difference between the two groups in terms of 20 meters running, standing medicine ball throwing, sitting medicine ball throwing, vertical jumping, horizontal jumping and flexibility values, and students participating in school sports had higher values. Bilim, Cetinkaya and Dayi (2016), in their study on 271 high school students from three different age groups who do and do not do sports, it was shown that men who do sports are significantly more successful in agility, speed and coordination tests in all age groups than men who do not participate in school sports. In the study conducted by Aydos and Kurkcu (1997), in which 123 students between the ages of 13-18 participated, it was revealed that the averages of horizontal jump, vertical jump and flexibility of the group that do sports are significantly different from the group that does not do sports. The fact that children do a branch under license is related to the economic level of the family. It is thought that the higher the education level of the family, the higher the economic income. In a study conducted by Caglayan and et. al (2004), it was stated that the education level of the families of children who do sports is higher than the families of children who do not do sports. Although the age groups are different in the studies conducted in the literature, the results show similarity. Based on these similarities, it is thought that physical fitness tests at a young age will be useful in directing children to sports and in choosing athletes for club coaches.

In the study, when the physical fitness elements of the students were compared in terms of children's participation in traditional children's games, it was determined that there was a significant difference in favour of the students who participated in the traditional children's games in the height, body weight, standing long jump test, sit-up test, bent-arm hanging test, 5x10 meter sit-up run tests. When the literature is examined; no research has been found related to traditional children's games and the subject of our research. However, in a study conducted by Sirin (2009), when the physical performance scores of the 14-year-olds who have been playing sports for at least 3 years in the infrastructure of the professional football team and the 14-year-olds who do not participate in school sports, the average height, body weight, meter running values, horizontal jump, vertical jump values and flexibility measurement values were found to be higher than the averages of the young people who did not participate in school sports. In this part of our study, within the scope of traditional children's games, inter-school competitions are organized under school sports and teams are formed by selecting students at each grade level for these competitions. At this point, bringing this information to the literature increases the importance of the research.

As a result, it has been revealed that the physical fitness factors such as height, strength and agility of the students who do sports and participate in traditional children's 
games, which we consider as physical activity, are in better condition than the students who do not participate in such physical activities.

\section{Conflict of Interest Statement}

The authors declare no conflicts of interests.

\section{About the Authors}

Aslihan Buksur was a Graduate Student at Tekirdağ Namik Kemal University, Department of Physical Education and Sports.

Dr. Umut Canli is an Associate Professor of Physical Education and Sports Education, School of Physical Education and Sports in Tekirdag Namik Kemal University, Turkey. His main research interest is in the area of strength \& conditioning and exercise neuroscience.

Dr. Cüneyt Taskin is an Assistant Professor of the Department of Physical Education and Sports Teaching, School of Kirkpinar Sports Faculty in Trakya University, Turkey. His main research interest is in the area of education systems.

\section{References}

Altinkok, M. 2006. The effects sample physical education program aiming motor movement patterns on the development of basic motor movements of children in 5-6 ages. Master's Thesis, Marmara University Institute of Educational Sciences, İstanbul.

Aydemir, İ., \& Bayansalduz, M. 2019. Physical activity and academic success. Gülten H. (Ed.), Sports in All Aspects (467-486.pp.). İstanbul, Guven Plus Grup Publishing.

Aydos, L., \& Kurkcu, R. 1997. Comparison of the physical and physiological characteristics of secondary education youth between the ages of 13-18 who do and do not do sports. Gazi Journal of Physical Education and Sport Sciences. 2(2):31-8.

Bilim, A.S., Cetinkaya, C.A., \& Dayi, A. 2016. Analysis of the physical fitness of students between the ages of 12-17 who do and do not do sports. Journal of Athlete and Performance Studies. 7:53-139.

Buyukozturk, Ş., Cakmak, E.K., Akgun, Ö.E., Karadeniz, S., \& Demirel, F. 2016. Scientific Research Methods. 21 ${ }^{\text {st }}$ Edition. Ankara: Pegem Academy.

Caglayan, A., Calik, F., Sivrikaya, K., \& Kahveci, M. 2004. Comparison of 12-15 age group students who do sports and those who do not, in terms of school success, $10^{\text {th }}$ ICHBER-SD European Congress and SBD 8th International Sports Sciences Congress, Antalya.

Hazar, F. \& Tasmektepligil, Y. 2008. Investigation of the effects of balance and flexibility on agility in the pre-pubertal period. Spormetre Journal of Physical Education and Sport Sciences. 5(1):9-12. 
Health, U.D.O., \& Services, H. 2008. Physical Activity Guidelines Advisory Committee. Washington DC: US Department of Health and Human Services.

Janssen, I., Katzmarzyk, P. T., Boyce, W. F., King, M. A., \& Pickett, W. 2004. Overweight and obesity in Canadian adolescents and their associations with dietary habits and physical activity patterns. Journal of adolescent health, 35(5), 360-367.

Kandir, A., \& Tumer, K. 2013. Analysis of early learning skills of five-six-year-old children from different socio-economic levels. Social Policy Studies 13(7).

Karakoc, B. 2009. Analysis of aerobic and anaerobic structures of field tests that are frequently used in young football players. Unpublished Master's Thesis. Ankara University.

Lopes, V.P., Rodrigues, L.P., Maia, J.A.R., \& Malina, R.M. 2011. Motor coordination as predictor of physical activity in childhood. Scandinavian Journal of Medicine \& Science in Sports. 21(5):663-669.

Opstoel, K., Pion, J., Elferink-Gemser, M., Hartman, E., Willemse, B., Philippaerts, R., \& Lenoir, M. 2015. Anthropometric characteristics, physical fitness and motor coordination of 9 to 11-year-old children participating in a wide range of sports. PloS One. 10(5).

Ortega, F.B., Ruiz, J.R., Castillo, M.J., \& Sjostrom, M. 2008. Physical fitness in childhood and adolescence: a powerful marker of health. Int J Obes. 32(1).

Pekel, H.A. 2007. Normative study on some variables in 10-12 years old children depending on the skill search in athletics (Ankara province example). Doctoral Thesis. Institute of Medical Sciences, Gazi University, Ankara.

Smith, J.J., Eather, N., Morgan, P.J., Plotnikoff, R.C., Faigenbaum, A.D., \& Lubans, D.R. 2014. The health benefits of muscular fitness for children and adolescents: a systematic review and meta-analysis. Sports Medicine. 44(9):1209-23.

Simsek, E. 2018. Evaluation of the differences in body compositions and some physical parameters of students who do and do not do sports. Master's Thesis, Istanbul Gelisim University.

Sirin, E. 2009. Comparison of some biomotoric developments of 14-year-olds who do sports and do not participate in school sports. Master's Thesis, Dumlupinar University, Kutahya.

Tabachnick, B.G., \& Fidell, L.S. 2013. Using Multivariate Statistics. $6^{\text {th }}$ Edition. Boston: Allyn and Bacon.

Taskin, G., \& Ozdemir, F.N.Ş. 2018. The importance of exercise in children. Gazi Journal of Physical Education and Sport Sciences. 23(2):131-141.

Zahner, L., Puder, J.J., Roth, R., Schmid, M., Guldimann, R., Pühse, U., Knöpfli, M., BraunFahrlander, C., Marti, B., \& Kriemler, S.A. 2006. School-Based Physical Activity Program to Improve Health and Fitness in Children Aged 6-13 Years "Kinder Sport studie KISS": Study Design of a Randomized Controlled Trial. BMC Public Health. 6(6):14. 
Aslihan Buksur, Umut Canli, Cüneyt Taskin

HOW DOES PARTICIPATION IN PHYSICAL ACTIVITY AFFECT

PHYSICAL FITNESS ELEMENTS IN CHILDREN AGED 5-9?

Creative Commons licensing terms

Author(s) will retain the copyright of their published articles agreeing that a Creative Commons Attribution 4.0 International License (CC BY 4.0) terms will be applied to their work. Under the terms of this license, no permission is required from the author(s) or publisher for members of the community to copy, distribute, transmit or adapt the article content, providing a proper, prominent and unambiguous attribution to the authors in a manner that makes clear that the materials are being reused under permission of a Creative Commons License. Views, opinions and conclusions expressed in this research article are views, opinions and conclusions of the author(s). Open Access Publishing Group and European Journal of Fitness, Nutrition and Sport Medicine Studies shall not be responsible or answerable for any loss, damage or liability caused in relation to/arising out of conflicts of interest, copyright violations and inappropriate or inaccurate use of any kind content related or integrated into the research work. All the published works are meeting the Open Access Publishing requirements and can be freely accessed, shared, modified, distributed and used in educational, commercial and non-commercial purposes under a Creative Commons Attribution 4.0 International License (CC BY 4.0). 